\title{
Sign and reality
}

\section{Victor Novoselov}

Department of Philosophy, Novosibirsk State Technical University, Novosibirsk, Russia

\section{Email address:}

viktor-novoselov@yandex.ru (V. Novoselov)

\section{To cite this article:}

Victor Novoselov. Sign and Reality, Social Sciences. Vol. 1, No. 1, 2012, pp. 1-6. doi: 10.11648/j.ss.20120101.11

\begin{abstract}
This article is devoted the semiotics analysis of concepts of reference. On the basis of the analysis the conclusion becomes, that the sign can display a reality only in the course of human activity. Denotation of a sign is a way of its use and interpretation. From the point of view of the theory of reference the parity between language and the world described by it is the relation of "isomorphism" or the biunique correspondence, i.e. such parity between elements (objects) of two sets (structures) when one certain element of the second set can be to some extent put each element of the first set in conformity.
\end{abstract}

Keywords: Sign Denotation Reference Meaning Denoting Signification

\section{Introduction}

One of the major problems arising at the analysis of sign systems, the problem of a parity of signs with objects of world around is. How much we spoke about language, its role in a life of people, especially - in knowledge, are compelled to pay exclusive attention to how words and language expressions are connected with other part of the world, with a reality - with that so much, "about what is spoken in language". The precondition that we speak not simply so, and about something is natural, we learn by all means something, and that presence of a subject of conversation (or knowledge) just and distinguishes conversation or knowledge of own and full sense from something, that only, it seems to that. Most likely, it is possible to consider this assumption as the primary factor which has caused that circumstance, that more often postulated type of communication of language and a reality is conformity (differently, the correspondence) and based on him representation. The concept of the correspondence entered still by Aristotle, means, that language structures somehow correspond to reality structures about which in this language there can be a speech. It assumes first of all, that any significant changes in a reality (understood as subject sphere of language) do not leave not mentioned language, and in him there are the structural changes somehow corresponding first. Concept attraction representative means, that conformity looks like display of structure of a reality by language structure is, accordingly, means, that we not only can conclude, perceiving new language designs, that with a reality, in a reality something has occurred, but also to judge on these designs character of changes in the world.

\section{The Concept of Reference}

The brightest result of influence of correspondencerepresentative representations about communication of language with a reality is the concept of reference. Under reference usually understand a kind of direct connection language expressions with a subject in the world. In narrow sense this communication can be understood as characterizing expressions in such a manner that they, being are used definitely in a certain context, specify in the unique object in the world and more on any. In this representation there were mixed at least two: on the one hand, it is generalization of the facts of successful instructions on subjects by means of such expressions; on the other hand - the belief called by correspondent-representative model that successes of such instructions are not casual, and are results of an existing state of affairs. Successfully and regularly to specify in something there is a function of the expressions, which in itself possess property to be directly connected with objects in which they can specify, i.e. have them as the reviewers. Thus in understanding reference it is possible to allocate at least two treatments:

1. Expression can be directly connected the relation reference with the unique subject or object in the world and more with any so only this object and any another can be its reviewer at the correct use;

2. Or expression can be so is connected with a certain set of objects, it is possible, even not obligatory final - such 
expansion reference usually name in volume or extensional of the term. Such representation about semantic characteristics of certain group of expressions and, accordingly, a certain structural part of language, has in turn generated a certain direction in the philosophical analysis of the language, characterized by construction of theories of reference. As it is theories, their problem not simply to specify in certain character of communication of expressions with subjects, but to explain it, i.e. to reveal those factors in the world, in language or, perhaps, in us which have caused such state of affairs.

However, if a sense reference theory of value that names admit specifying on something and thanks to this characteristic having values it appears unimportant, on what type of essence they specify. Meanwhile, our usual representations about the world are that, that if we try to judge him not through a language prism we, as a rule, give due to those distinctions which we name the ontological. At higher level of a discourse we can distinguish them as essence of different kinds concerning which to "exist" each time a miscellaneous means. Reference, according to ordinary representations, a word and word-combinations meanwhile do not fix these distinctions: "unicorn" as a name grammatical is worse nothing, than "bull"; " The thought "," sense "- do not differ grammatical from" a table "and" a chair "etc. We can designate with equal success thus the subjects possessing various ontological statuses, including concepts about subjects. It is obvious, that such terms as, for example," the bull "and" a unicorn ", reflected corresponding ontological distinctions, their values - semantic characteristics - should allow establishing these distinctions. But, if value of the term consists in it reference on what basis such can be made? On the other hand, we have ways to fix the necessary ontological distinctions through the statement of distinctions between types of signs which can characterize those or other kinds essences and which, say, for individual objects, localize in space and time, intuitively not such as for senses or mental essences. The simple decision to which philosophers sometimes resorted is based on such intuitions - to spend a line of demarcation between existing and nonexistent on these qualitative distinctions. But at such approach reference does not guarantee existence and then, for example "anything", whose use in language so is similar to the use of names, it can quite be treated as a name of any essence (for example, not existing). Other known objections against such decision consist in instructions on absurdity following from it not only statements of existence concerning something nonexistent, but also - negations of its existence.

W. V. O. Quine has named problems such problems "Plato's beard": nonexistent in any sense exists, as there is something about what there is a speech [4]. But in what relation it is possible to say what any named subject exists so far as is instructions subject?

\section{The Ontological Problems of Refer- ence}

If the theory of reference accepts a call from the party of ontology she should solve somehow and these problems: concerning the same factors which, according to the given theory, cause of reference, it should be established, that they give the bases as well for carrying out of corresponding distinctions in borders assumed reference to a significant part of language. These distinctions should be spent or so that to cut everything, that only it seems reference, but is not that, as assumes a recognition undesirable essence, or - somehow differently. To solve these problems - ontological problems of reference - it is possible at least in two ways: metaphysical - it consists in searching for the factors causing reference, in the world or in ourselves, but not in language. The second deserves the name analytical (under the name of that tradition in which frameworks it has received the greatest development in the XX-th century) - it consists in search of factors of the specified type (in other words, criteria) in the language.

One known decision of problems of the marked kind consists in a recognition language unit not the term - not which is supposed reference significant - and certain comprehensive in relation to the term whole - offers, a proposition or the statement. Obvious communicative advantage of such comprehensive units (than them considered) consists that we can solve certain communicative problems with their help without attraction of additional theoretical preconditions. Easier to say the term, as a rule, happens insufficiently for that understanding, that speaking wishes to tell, whereas pronouncing of the offer which are switching on the given term, with an enviable regularity reaches the necessary result. Thus such comprehensive units will possess the various semantic statuses, at least, in one essential relation: one is considered true, and another - false. So, Frege recognizes, that value of the offer is it truth value. Under truth value of the offer he understands that circumstance, that it is true or false. «Any narrative offer, depending on values of words making it, can be considered, thus, as a name which value if, of course, it is available, will be either true, or lie» [1].

If this distinction is accepted as criterion of the ontological importance it becomes clear - as expressions "bull" and "unicorn" ontologically differ. However, value of corresponding comprehensive units of language - not less problematic matter, than reference ofthe term: conditions of definability of such values far are not always clear, and is far not for all language units such. In this case the question can be put so: whether it is possible to consider in general compound values definable irrespective of definiteness of values (terms) making them?

The positive answer to this question means, that value of the corresponding compound whole is directly defined by its communications with something out of language - with a reality: it enters into considerations other kind of corres- 
pondence-representative relations - or with any even more comprehensive whole. It, in turn, assumes the decision of other question: whether it is possible to count on the decision of ontological questions one or in another way, accordingly? The negative answer from its part, assumes search of such semantic characteristics of terms which, on the one hand, would not require a prop from ontological preconditions and, with another - would allow fixing demanded ontological distinctions: the decision of the specified problems in this case remains theory business reference.

In the modern philosophical literature some preliminary distinction meanwhile is entered, that the reference theory, and to what there can correspond concept" the value theory "can be designated by the term". As for the same expressions which, being considered reference language units, are subjects of theories reference, can exist and there are the theories explaining them of value without a mention reference, it will be pertinent to clear demarcation principles between two kinds of theories from which we want to proceed:

1. Value theories assume, what offers or statements are primary carriers of semantic value in language, i.e. to know, what does these units of language significant, for the answer to a question "That can essentially do significant all other expressions of language (which values in general can have)?" The reference theory, on the contrary, consider terms and other expressions of language from which such complexes as offers or statements, can consist, primary in similar, but opposite sense - i.e. to know that does their significant, means to know, at least, partly in what value of the offer or the statement consists. At such understanding of this distinction of the theory of value for expressions, presumably, reference the type, asserting, that other factors not reference-constancy concerning established values, pertinently to subdivide into two kinds. The first - the theories building the explanations on the basis of preliminary established roles of corresponding expressions in formation of values of larger language complexes - offers or statements, or propositions if those admit primary carriers of value - will be value theories in the sense specified above. The second, more likely, find out signs reducing in relation to concept reference the theories aimed at distribution of characteristics, usually connected with reference, between other factors, but it is not obligatory with attraction of general theory of value any more (in the sense specified above)

2. Whether if the negative answer to a question is accepted it is possible to consider compound values definable irrespective of definiteness of values making them, the value theory (for natural languages), most likely, cannot be constructed without a support on any theory of reference; in this sense reference constancy in relation to values, at least, some (but, probably, rather considerable number) types of language expressions.

Proceeding from distinction of the theory of value and the theory of reference it is necessary as well to distinguish concepts "subject" and "object". It is supposed to understand everything As a subject, that can be reference con- nected with language expressions, irrespective of the ontological status whereas "object" here designates not only that is qualitative, but also numeral, excellent others reality unit, i.e. the reviewer, individualization which depends on the ontological status ordered corresponding - subject - qualities.

\section{The New Reference Theory}

The big attention of the theory reference is given within the limits of analytical philosophy. Throughout all history of analytical philosophy the value problem was and remains to one of its central subjects. Semantic researches of last decades underline once again indefatigable interest of philosophers to this problem. It is possible to tell without exaggeration, that the "anti-mental" criticism of the "traditional" theory of value is one of the most important events in analytical philosophy of last time. The beginning to this criticism was put by founders so-called "the new reference theory" which number includes the visible American philosopher and logician Hillary Putnam[3].

It is possible to understand is better a place of the new theory of reference in a context of modern researches on a value problem if to look at it as on display of one important tendency in development of philosophy of language. Since Descartes and Lock's times philosophers, as a rule, adhered to that point of view, that words and expressions of our language are signs on ideas and are used first of all for expression of our thoughts. J. S.Mill and G.Frege have put an end to such understanding of language, having proclaimed, that our words serve for a designation of objects in a reality, instead of ideas in our consciousness. The basic function of language, from their point of view, articulation of subjects in the world surrounding us to state about them true statements is. Having placed to the place of mental images world around subjects. Mill and G. Frege, however, have not completely expelled ideas from the value theory. So, it agrees Frege, the word meaning represents twocomponential education: The word designates some object and expresses some sense (or idea), i.e. that we mentally seize when we understand a word. As "sign" Frege understands "any designation acting in a role of a proper name, which value is the certain subject (in the widest sense of this word), but not concept and not the relation» [1].

In a sign it is allocated two components: the sense and value «... some sign (a word, a word-combination or a graphic symbol) is thought not only in connection with designated which it would be possible to name value of a sign but also and because I would like to name the sense of a sign containing a way of a reality [designated] $\gg[1]$. The designation of one subject can consist also of several words or other signs. For brevity each such designation Frege names a proper name.

In its opinion, the sense of a proper name will be clear to everyone who sufficiently knows language or set of designations to which it belongs; however value of names if that is available, shined thus only on the one hand. Correct 
communication between a sign, its sense and value should be such that to a sign there corresponded certain sense, and to sense, in turn, - certain value while to one value (one subject) corresponds not only one sign. The same sense is expressed differently not only in different languages, but also in the same language. However, there are exceptions of this correct communication. Certainly, in perfect set of signs to each expression there should correspond only one certain sense, however natural languages far not always satisfy to this requirement. Thus, even if some sense is understood, it yet does not provide presence of value [1].

When a word use in the usual image then about what wish to tell, is its value. but sometimes wish to tell something about words or about their sense. Such happens, for example, when we pass another's words by means of direct speech. Then words said by us designate first of all words of other person, and only these last have usual value. In this case we deal with signs on signs. Thus, to a verbal image standing so-called cannot be attributed usual value. Till now Frege considered sense and value only such expressions, words and signs which he named proper names. Now he addresses to a question on sense and value of the whole narrative offer which contains some thought. «Whether we should consider this thought as its sense or how its value? We will admit that the offer matters. If in him we replace any word with other word with the same value, but with other sense it cannot affect value of the offer in any way. However we will see that the thought in that case will change»[1].

Thus, the thought is not value of the offer, it should be considered, more likely, as sense of the offer. But how then to be with value? Whether it is possible to ask in general such question? Perhaps, the offer as a whole has only sense, but has no value? Anyway, it is possible to expect, that there will be offers which - the same as also their some parts - make sense, but have no value.

Hence, about value of the offer speech can go only when value of its components is established, and this question can be put in only case when us interests it truth value.

Frege, thus, recognizes, that value of the offer is it truth value. Under truth value of the offer he understands that circumstance, that it is true or false. «Any narrative offer, depending on values of words making it, can be considered, thus, as a name which value if, of course, it is available, will be either true, or lie» [1].

If value of the offer is it truth value all true offers, on the one hand, and all false offers, with another, will have the same value. "Therefore value in itself us does not interest; however and the naked thought, i.e. sense in itself, too does not bear in itself new knowledge. Us connection of thought and its value, i.e. it truth values interests only. The judgment can be considered as transition from thought to it truth value».

Thus, Frege spoke about sense as about a way value display. However as pure value - not an image and not representation can "be shown"? Obviously, speaking about a way of the phenomenon of value, it is not necessary to think of display of any difficult structure in mysterious unity: value like a thing and consequently is simple and is indivisible. Its system mutual relations can be difficult. We will tell, "dark blue" it can be shown in communication "dark blue/red" (cold / warm color), "dark blue/white" (color of a life/color of emptiness) etc. Thus, senses of value are those system communications which are at present satirized also that category in which frameworks they are united and opposed.

Thus, any use of value - intelligently, that is for each moment of time any system communications are claimed, and any - are not present.

If we ask today a question, whether represents myself a word the form figurative or symbolical representation to the information will affirm, most likely, the last.

The big attention of the theory reference gives also B. Russell. In article «On Denoting» [6] Russell enters concept of "a designating phrase» as which he understands following phrases: the person, some person, any person, each person, all people, the reference of the Earth round the Sun, the center of weights of solar system during the first moment of the twentieth century etc. Such phrases are meaning exclusively owing to the form. Russell allocates three types of such phrases:

1. The phrase can be designating and still nothing to designate;

2. The phrase can designate certain object;

3 . The phrase can have equivoque.

Considering the theory of value Frege, Russell recognizes that its allocation in designating phrases of two elements -meaning and denotation as a whole is productive, since allows avoiding infringement of the law of the contradiction. It is necessary to note, by the way, that the English verb ' mean ' cannot be translated quite precisely neither to French, nor on German language. Any of following verbs: ' meinen ', ' bedeuten' , ' voiloir dire ' ' signifier ', - any of these verbs is not an exact equivalent of English ' mean '.

Nevertheless, Russell notices, that acceptance of the point of view that the designating phrase expresses sense and designates value, leads to certain difficulties when value is absent. Can seem, that such judgments are absurd. Actually they those are not owing to that their initial hypotheses are false. Thus, according to Russell if we recognize, that two parties - sense and value, cases in which, apparently, value is absent have designating phrases, call difficulties as in acceptance of that value really is present, and at acceptance of that it is absent [6].

This concept of "sense" (at Mill- concept of "connotation") also forms that "mentalist" element which has allowed a number of modern philosophers to carry the theory of value Frege to Descartes "mentalist" tradition. This mentalist element is even more strengthened by postulate Frege that sense of language expression defines its subject value, or, in modern terminology, it reference. It should be understood so, that the reviewer of a word will be that object which satisfies to the characteristics which have been switched on in sense of this word, i.e. sense, sets "way" to 
the reviewer, allows to correlate a word with a certain element of the world. Frege semantic concept has in many respects set a paradigm of all subsequent reasoning on value within the limits of analytical philosophy. At the same time in development of philosophy of language after Frege the distinct tendency to get rid of concept of sense is looked through and, thus, to finish the business begun J. S. Mill and G. Frege. It speaks not in the last instance that the concept of "sense" does not give in to expression in a formal kind and he is difficult for analyzing logical-mathematical methods. Therefore analytical philosophers for whom the severity and accuracy of the analysis always were the important attributes of a method of philosophizing, aspired to reduce to a minimum or in general to eliminate from the theory of value concept of sense. The history of analytical philosophy in the XX-th century knows many attempts to present the relation between language and the world as direct, not mediated any mental essences. The new theory of reference is the next attempt in this direction. Its main thesis is not new: reference the major categories of language expressions (proper names, terms of natural kinds and indexes expressions) it is established without sense intermediary. Novelty of this theory is made by a way of a substantiation of this thesis and the mechanism of an establishment offered in exchange reference [8].

As it was already marked, the new theory of reference has been offered as an antithesis to the traditional approach. But what in this case it is understood as the "traditional" theory? Supporters of the new theory of reference, as a rule, specify, that the traditional theory of value goes back to ideas of Frege and Russell and represents that set of positions which usually state in textbooks and a reference media on semantics and against which modern philosophers when argue on value obviously or implicitly lean. At the formulation of the traditional theory modern writers usually use not offered Frege concepts of sense and subject value, and synonymous it concepts intentional and extensional, entered by R. Carnap. Besides theses Frege about two components of value and about definition extensional by intentional the traditional theory, according to its modern critics, contains also position that sense (or intentional) language expression is represented by set description properties and characteristics which are inherent in object designated by it (or to objects). This position goes back to the description theory Russell according to which even the usual proper name is "hidden" or "reduced" description. Very important role in the traditional theory of value is played by concept of analytical true which allows describing the establishment mechanism of reference. The offer is considered analytical if its validity is established on a basis intentional of the terms entering into it. If $\mathrm{P}$ - the property entering in intentional of term T the statement "All T is P" is analytically true, and according to traditional treatment of analytical true it is aprioristic and necessary, that the possession the characteristics which have been switched on in intentional of the term from here follows, forms a necessary and sufficient condition for object reference to exten- sional the given term.

Putnam has developed the critical arguments and constructive semantic ideas with reference to terms of natural kinds. Terms of natural kinds are the words serving by names of natural substances, animal, plants and physical sizes (for example, "water", "tiger", "lemon", "electricity" etc.). The majority of scientific terms concern this category of language expressions. Besides such general characteristic it was not offered any strict definition of terms of natural kinds, however their theory of reference which therefore and name the theory of natural kinds urged to open specificity of these terms [2].

So, the basic idea of this argument consists in the following: any of the properties which are usually switched on in intentional of the term of a natural kind, is not necessary for analytical definition of this kind as according to traditional interpretation of analytical true it should be aprioristic and necessary, and no of the specified properties can be considered necessary as the object accessory to some natural kind cannot depend on possession these properties. However intentional words can contain description essential properties of a natural kind which are necessary.

Putnam second argument against the traditional theory of value lifts deeper layer of problems. According to this argument the traditional theory of value leans against two assumptions which cannot be simultaneously true. The first assumption establishes, that the understanding of a word meaning is connected with stay in certain mental (or mental) a status. This assumption underlies a characteristic identification for the traditional theory of intentional (or sense) with concept and in recognition of that concepts should be mediated somehow mental representations. The second assumption is connected with that fact, that an intentional word defines it extensional in the sense that intentional forms a necessary and sufficient condition for object occurrence in extensional. If to accept the specified assumptions it is necessary to recognize, that "the event in our head" should determine that, on what our words specify.

However, considers Putnam, the mental condition cannot define Putnam extensional of the term.

Their basic thesis in the decision of this problem can be formulated so: reference of the specified expressions it is established thanks to external not mental factors.

So, it agree Putnam, two factors participate in an establishment reference of terms of natural kinds: social (owing to that there is "a division of linguistic work") and natural (thanks to that "natural kinds play a part in an establishment of extensional terms which specify in them" Putnam argues as follows. According to the traditional theory of value the person understands some word if has acquired its sense. But considering, that the sense of a word represents often difficult enough set of the information, it is necessary to recognize, that very much the small number of people owns senses and, hence, understands words. Then the huge majority of native speakers could be accused that they do not understand those words which use. But such assumption, according to Putnam, is absurd as to understand and 
use a word; it is absolutely unessential to know in full Frege sense of a word. Quite enough, considers Putnam, to rely on experts who own this sense, but also, own a recognition method [4].

\section{Conclusions}

The new decision offered by Putnam, already completely in the spirit of Wittgenstein [7]. According to this decision value of linguistic expressions is that proves to be in our words and offers. When we hear or we read words and offers, we do not perceive them as simple "sounds and signs" into which the value which is out of their and present at our consciousness as certain "mental essence" should be inserted". We perceive value in words and offers, but from here does not follow, considers Putnam, that value is inherent in them by nature. Our words and offers possess value because «the technics of the use "thanks to whom value shows the true worth in them takes place defined. Here Putnam uses Wittgenstein's idea that we can «see the person of one activity in another (as we see the human face image in various configurations of lines and points). One activity can prove to be in another thanks to that all kinds of human activity are closely coordinated with each other, forming the difficult and branched out system. Therefore and the thinking is the not separately standing activity which is not supported by any other kinds of activity. It is twisted in difficult system an expert both linguistic and not linguistic [4].

So, on an example of semantic ideas by Putnam, it is possible to ascertain one more attempt to relieve the theory of value from mentalist assumptions. Having begun with that negation that the word meanings presented in the mental images" in consciousness of the person, define reference of these words, Putnam has gradually come to not mentalist treatment of value. Definition of values as concepts which represent "not mental representations", and the signs used situational properly was the first step in this direction. However in this position yet has been completely got rid mentalist, as the active role of consciousness (in particular, conceptual schemes) in creation of the world surrounding us was assumed. Therefore value "removal" for limits of consciousness and its coordination with system various human an expert, with that fact was following step, that one activity can prove to be in another.

Thus, it is necessary to recognize, that this attempt to get rid of concept of sense and the "mentalist" assumptions connected with it promoted formation of more adequate and deep representation how language functions and as its interaction with world around is carried out. The criticism of the traditional theory of value has revealed the real problems connected with description by treatment of value. But in essence, the new theory of reference contains the decision for the most simple case, namely - for a case of the usual use of names, and does not offer any ways of the decision of this problem in case of indirect speech though this case represents the greatest difficulty for semantics. And constructive ideas of supporters of the new reference theory are connected with strong enough assumptions which validity is not so obvious.

Thus, from the point of view of the theory of reference the parity between language and the world described by it is the relation of "isomorphism" or the biunique correspondence, i.e. such parity between elements (objects) of two sets (structures) when one certain element of the second set can be to some extent put each element of the first set in conformity.

\section{References}

[1] Frege G. The Meaning and denotation. http:// www. philosophy.ru/library./frege/02.html.

[2] Putnam H. The Meaning of Meaning. - In: Putnam H. Mind, Language and Reality. Vol. 2. Cambridge Mass., 1975. Pp. 215-271.

[3] Putnam H. Representation and Reality. Cambridge Mass., 1988.

[4] Quine W. V. Two Dogmas of Empiricism. — In: Quine W. V. From a Logical Point of View. Cambridge Mass., 1953. 2nd ed. Cambridge Mass., 1961.

[5] Quine W. V. Word and Object. Cambridge Mass. - N.Y., 1960.

[6] Russell B.On Denoting //The Philosophy of Language (3 edition), A. P. Martinich (ed.). - Oxford University Press, 1996. P. $112-126$.

[7] Новоселов В.Г. Проблема интерпретации знака и неограниченный семиозис - Исторические, философские, политические и юридические науки, культурология и искусствоведение. Вопросы теории и практики. - №8(14), ч.2, с. 160-163. - Тамбоов,2011.

[8] Новоселов В.Г. Значение и интерпретация в контексте семиотики культуры. - Философия образования.- 2010.№4(33).- С.278 - 285. Новосибирск, 2010. 